\title{
Estudio de prevalencia de serotipos enteropatógenos de Escherichia coli en deposiciones de niños que habitan una población suburbana de Santiago
}

T. M. Guillermo Figueroa Gronemeyer.*

\begin{abstract}
4.445 staol cultures from children living in a sub urban population were prucessed during a 21 months longitudinal study.

Appropriate bacteriviogical technique were used to identificate enteropachogenic escherichia coli (EPEC) trom stools of children with or without diurrhea. Total isnlation trequency of epec was $1.6 \%$. In 468 samples frota subjects witl diantes the isulatisn rate increased to $6.6 \%(p<0.001)$.

The must prevalent ECEP serotypes were 0119: K69 and $0126: K 71$ as they were recuvered in $73.6 \%$ of the tutul sample and in $60.6 \%$ of diarrhea samples the above mentioned prevalence rates were compared with those recuvered at the same lime by the national referente cenler frum Hespital samples, in the latter eases EPEC frum 011]: KJis serutypes had the higlest prevalence. This could be explained by selection mexhanisms uperaled by antibiutics which allow the survival of resistant ur virulen strains in the Hospital Milieu.
\end{abstract}

De los métodos disponibles en Chile para el estudio etiológico de la diarrea aguda infantil, el más utilizado es la serotipificación de cepas de E. coli aisladas de deposiciones. Mediante esta técnica se liega a incriminar a determinados serotipos como agentes causales de esta prevalente enfermedad, tal vez por esta misma razón estos agentes ocupan en nuestro pais el primer lugar entre las causas de diarrea aguda de origen infeccioso.

De acuerdo a informes recientes del Centro de referencia del I.B.Ch., la prevalencia de los serotipos de E. coli enteropatógenos (ECEP) en los años 1977 y 1978 mostró que un $31,3 \%$ de las cepss por ellos estudiadas correspondian al serutipo de E. coli 0111: B4, en segundo término E. coli 055: B5 con un $13,9 \%$ de los aislamientos y a continuación los serotipos 044,0125 y 026 , con más de $9 \%$ cada uno; en resumen, los cinco serotipos mencionados daban cuenta de más del $73 \%$ de los aislamientos de ECEP provenientes de coprocultivos de niños hospitalizados con sindrome diarreico agudo.

Nuestro objetivo al realizar esta investigación es intentar determinar la frecuencia de aislamientos y prevalencia de los serotipos enteropatógenos de $\mathbf{E}$.

*Unidad de Microbiolugía, INTA. coli a nivel de niños que habitan una población suburbana de Santiago de bajo estrato socioeconónjico y deficientes condiciones de saneamiento ambiental (Población El Vivero, de Majpú), el período de muestreo comprende desde julio de 1977 hasta abril de 1979.

\section{MATERIAL Y METODO}

A 197 niños de entre 0 y 4 años se les realiza coprocultivo mensual y cultivos extras cada vez que presentan enfermedades diarreicas, la metodologia en ambas condiciones es semejante.

\section{Toma y transporte de la muestra}

Las muestras fueron tomadas por personal entrentdo, mediante una espátula de madera y depositada en un frasco con S.F. (7\%) como medio de transporte y enviadas al laboratorio en un plazo máximo de 4 horas.

\section{Coprocultivos}

Todas las muestras se siembran en placas de XLD agar, EMB agar y S.S. agar, además se utiliza caldo selenito como preenriquecedor, el que luego de 17 
horas de incubación se repica en placa de agar sulfito de bismuto. La biotipificación se realiza mediante técnic as habituales. (")

En los coprocultivos con desarrollo de E. coli a por lo menos una colonia se le realiza serotípificación utilizando sueros poli y monovalentes O:K (BioMerieux-Francia).

La metodología empleada no sólo orienta a la pesquisa de ECEP, sino también a otros enteropatógenos bacterianos como salmonella o shigella, que serán motivo de otro reporte, cabiendo sí anotar que nunca que se aisló ECEP lo hizo asociado con otro enteropatógeno bacteriano.

\section{RESLILTADOS}

Mediante técnicas apropiadas se realizan $\mathbf{4 . 4 4 5}$ coprocultivos, de ellos se aislan 72 cepas de ECEP. lo que significa un porcentaje total de aislamiento del $1,66 \%$ ('Tabla 1 ), el número de muestras provenientes de niños con diarrea durante el periodo de ensayo es de 472 muestras y el total de ECEP aisladas en este grupo alcanza a 33 cepas, con un porcentaje de aislamiento del orden de $6,62 \%$ (Tabla 1), el número de muestras procesadas a niños sin diarrea es de 3.977 y de ellas se aíslan 39 cepas de ECEP, con una frecuencia de aislamiento del $1,02 \%$ (Tabla 1). El estudio estadístico de la frecuencia de aislamientos de ECEP entre niños con y sin diarrea muestra significancia con valores de $X^{2}=97.7597 y$ un $p<0.001$.

En la Tabla 2 se observa la distribución por serotipos de las 72 cepas de ECEP aisladas durante el proyecto.

\section{Tabla 2}

Distribución de 72 serotipos enteropatógenos de E. coli $(N=4.445)$ (Proyecto Majpú 1977-1979)

\begin{tabular}{ccc}
\hline Serotipo & N. ${ }^{*}$ cepas & \% del total \\
\hline $0119: \mathrm{K} 69$ & 27 & 37.5 \\
0126: K71 & 25 & 34.7 \\
$0125: \mathrm{K} 70$ & 4 & 5.5 \\
$0128: \mathrm{K} 67$ & 4 & 5.5 \\
$086: \mathrm{K} 61$ & 3 & 4.1 \\
$055: \mathrm{K} 59$ & 3 & 4.1 \\
$0127: \mathrm{K} 68$ & 2 & 2.7 \\
026: K60 & 2 & 2.7 \\
0142: K86 & 1 & 1.3 \\
0111: K58 & 1 & 1.3 \\
\hline
\end{tabular}

INTA 79

En conjunto, como se desprende de la Tabla 1, los serotipos 0119: K69 y 0126: K71 significan un $73,6 \%$ de las cepas aisladas, no observándose diferencia significativa cuando se estudian los grupos con diarrea $(62,4 \%)$ y sin ella $(82,5 \%)$.

\section{DISCLSION}

Los resultados entregados en eate informe permiten obtener conocimiento de la prevalencia de serotipos de ECEP en una población infantil suburbana de Santiago y mostrar importantes diferencias en relación a los informes de aislamiento de estos agentes

\section{Tabla 1}

Frecuencia de aislamiento de serotipos enteropatógenos de E. coli

(Proyecto Maipú 1977-1979)

\begin{tabular}{lrccc}
\hline Muestras & $\mathrm{N}$ & $\begin{array}{c}\text { Cepas acep. } \\
\text { aisladas }\end{array}$ & $\begin{array}{c}\% \\
\text { aislamient. }\end{array}$ & $\begin{array}{c}\% \\
\text { serotipos } \\
0119 \text { y 0126 }\end{array}$ \\
\hline Total & 4.445 & 72 & 1.66 & 73.6 \\
Diarrea & 468 & 33 & 6.62 & 60.6 \\
Sanos & 3.977 & 39 & 1.02 & 82.05 \\
\hline
\end{tabular}

$\mathrm{X} v^{2}=97.7597$

INTA 79

p $(G L=1)=<0.001$ 
en muestras provenientes de niños hospitalizados de edades semejantes ( $T_{\text {abla }} 3$ ), estas diferencias persisten aun cuando se comparen sólo las muestras provenientes de niños con diarrea.

Por otra parte, de los datos estadísticos mostrados parece desprenderse que los serotipos de ECEN

\section{Tabla 3}

Comparación de frecuencia de serotipos de E. coli Proyecto Majpú en relación a estudios contemporáneos realizados en niños hospitalizados de nivel Etario y socioeconómico semejante (Informe del Centro de Referencia IBCH)

\begin{tabular}{ccc}
\hline Serotipos & $\begin{array}{c}\text { Proyecto Maipú } \\
(\%)\end{array}$ & $\begin{array}{c}\text { Centro de Refer. } \\
\text { IBCH }(\%)\end{array}$ \\
\hline 0119: K69 & 37.5 & 7.4 \\
0126: K71 & 36.1 & 0.8 \\
0125: K70 & 5.5 & 9.05 \\
$0128: K 67$ & 5.5 & 1.5 \\
$086:$ K61 & 4.1 & 6.0 \\
$055:$ K59 & 4.1 & 13.9 \\
$0127:$ K68 & 2.7 & 2.1 \\
$026:$ K60 & 2.7 & 9.6 \\
$0142:$ K86 & 1.3 & 0 \\
$0111:$ K58 & 1.3 & 31.3 \\
$044:$ K? & 0 & 9.88 \\
\hline
\end{tabular}

INTA 79 se aíslan con una frecuencia significativamente mayor en niños con diarrea que en aquellos sin esta enfermedad, nos parece importante este puntio, ya que existe discusión acerca de la conveniencia de seguir realizando la serotipificación para el diagnóstico de ECEP.2, 3, 4, 51

Las diferencias de prevalencia, nos parece, podrían explicarse pensando en la selección de determinados serotipos en el ambiente de hospital, ésta estaria mediada por el elevado uso de substancias antibióticas, o a caracteres particularmente agresjvos (cápsula - polisacáridos de superficie - factores antifagocitarios) determinantes que provocarian cuadros más severos en huéspedes susceptibles que llevarian a la internación del paciente en el hospital, la dilucidación de estas hipótesis nos parece campo para futuras investigaciones.

\section{REFERENCIAS}

I Eduards, P. R., and Eaing, W, H. Identitication of Entembacteriaceae. 3rd kd. Cu. Minneapulis. Burgess Publishing Company, 1972.

2 Echeverria, $P_{\text {; }}$ Chang, C.P., and Smith, D. Enterotoxigenicity and insusive capacity of "Enterupathogenic" serotypes of Escherichia coli. J. Y'ediatr. 84: B-10, 1976.

3 Gurwith. M. J.; Wiseman, D. A., and Chow, P. Clinical and laboratury assesment of the pathogeneciny of seroryped enteropathagenic Escherichia coli. J. Infect. Dis. 135: 736-743, 1977.

4 Letine, M. M.; Bergkist, E.J.; Natin, D. R.; Waterman, D. H.; Hornick, K. B.; Young, C. R.; Steten, S.; Rowe, B. Escherichis coli strains that cause diarthen hut do not produce heat-labile or heal-stable enterotoxins and are non invasive. Lancet 1 : 1119 $1122,1977$.

5 Fanner, J.J. III; Davis, B. R,; Cherr, W. B; Brenner, D.J;; Dowell, V. R. Jr.; Dalows, A. Criteria Ior "Enteropalbogenic serotypes" of E. coli. J. Pediatr, 90: 1047-1049, 1977. 